Jacques Prévotat, Jean Vavasseur-Desperriers (dir.), Les « Chrétiens modérés » en France et en Europe, 1870-1960

Villeneuve-d'Ascq, Presses universitaires du Septentrion, 2013, 486 p.

Pascale Gruson

CpenEdition

Journals

Édition électronique

URL : http://journals.openedition.org/assr/26542

DOI : $10.4000 /$ assr.26542

ISSN : $1777-5825$

Éditeur

Éditions de l'EHESS

Édition imprimée

Date de publication : 31 décembre 2014

Pagination : 280

ISBN : 978-2-7132-2467-6

ISSN : 0335-5985

Référence électronique

Pascale Gruson, « Jacques Prévotat, Jean Vavasseur-Desperriers (dir.), Les « Chrétiens modérés » en France et en Europe, 1870-1960 », Archives de sciences sociales des religions [En ligne], 168 | 2014, mis en ligne le 19 mai 2015, consulté le 22 septembre 2020. URL : http://journals.openedition.org/assr/ 26542 ; DOI : https://doi.org/10.4000/assr.26542

Ce document a été généré automatiquement le 22 septembre 2020.

(C) Archives de sciences sociales des religions 


\section{Jacques Prévotat, Jean Vavasseur- Desperriers (dir.), Les « Chrétiens modérés » en France et en Europe, 1870-1960}

Villeneuve-d'Ascq, Presses universitaires du Septentrion, 2013, 486 p.

Pascale Gruson

\section{RÉFÉRENCE}

Jacques Prévotat, Jean Vavasseur-Desperriers (dir.), Les « Chrétiens modérés » en France et en Europe, 1870-1960, Villeneuve-d'Ascq, Presses universitaires du Septentrion, 2013, $486 \mathrm{p}$. 
1 La modération pourrait-elle être une vertu citoyenne remarquable? Appliquée aux bourgeoisies catholiques d'Europe entre 1870 et 1960 , telles que confrontées à une sécularisation grandissante de leur environnement et une déstabilisation de leurs repères, la question a manifestement un sens. Pouvaient-elles en effet échapper aux positions extrêmes de l'Action française (une référence fréquente) ou aux débats importants nés de la crise moderniste (dont il est peu question dans l'ouvrage)? Un colloque réuni à Lille (de fait un lieu qui fut longtemps un bastion de la bourgeoisie industrielle catholique) en 2005 et 2006 et dont les Actes viennent d'être publiés a souhaité donner une visibilité à des mouvements associatifs, à des groupes de réflexion, à des personnalités qui, loin des

Jacques Prévotat Jean Vavasseur-Desperriers (dir. svec la collaboration de Jean-Marc Guistin

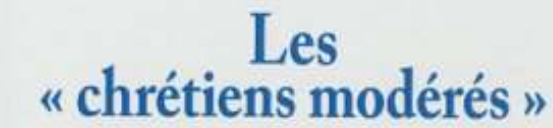
en France et en Europe I870-I960

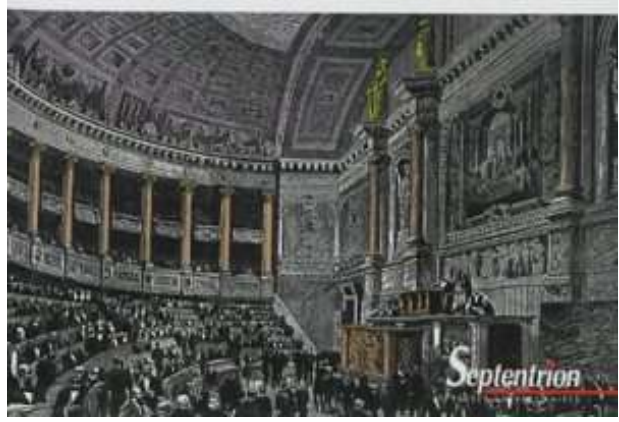
fureurs médiatiques, ne sont pas pour autant restés indifférents à leur environnement et $\mathrm{y}$ ont pris des initiatives importantes.

2 Le colloque proposait trois axes de travail. L'un portait sur les courants catholiques modérés dans une Europe désormais sécularisée; s’il y est question des protestants, c'est plutôt comme antithèse, car ceux-ci ont été engagés plus visiblement dans les grandes réformes de la III $^{\mathrm{e}}$ République. L'autre se focalisait sur les nombreux mouvements catholiques qui ont vu le jour dans la France de la III $^{\mathrm{e}}$ et de la IV $^{\mathrm{e}}$ République. Le troisième s'intéressait à quelques personnalités représentatives de cette modération souvent ardente.

3 Il n'est pas tout à fait surprenant de se retrouver alors dans l'univers des droites modérées et centristes, celles qui ont été analysées par René Rémond. Le colloque se déroulait d'ailleurs sous son autorité et il put en proposer une conclusion éclairante, peu de temps avant sa mort.

4 Mais quelles sont les qualités particulières de ces acteurs dévoués du monde catholique?

5 Ils sont tout d'abord fidèles à l'autorité de l'Église. C'est pourquoi, loin de l'Action française mais dans la suite de Léon XIII, ils se sont ralliés à la République. Ils ne sont pas insensibles aux vertus de la démocratie, mais avec circonspection : comme Anatole Leroy-Beaulieu, ils sont alors sensibles à l'œuvre de Tocqueville. Ils ne détestent pas la laïcité. Pendant la Première Guerre mondiale, ils ont été patriotes, mais ils ont aussi entendu en 1917 l'appel à la paix de Benoît XV. Ils ont participé à des missions de paix dans l'entre-deux-guerres et ont apprécié la SDN.

6 Parce qu'ils sont fidèles à l'autorité de l'Église, ils sont très anticommunistes, mais ils ne sont pas indifférents aux questions sociales et prêtent attention à l'encyclique Rerum novarum. C'est dans cette fidélité essentielle et avec les valeurs qui lui sont associées 
qu'ils sont attentifs au monde qui les entoure. Ils se sont alors engagés dans divers mouvements associatifs ouvrant à une réflexion plus ou moins approfondie sur les problèmes du moment. Et toujours ils ont considéré que cet engagement était, devait être, apolitique. En fait, tel n'était pas toujours le cas, mais il leur était important de marquer leur différence avec une politique, selon eux trop politicienne, en tout cas prise dans l'urgence des problèmes de l'instant.

7 Si l'on connaît assez bien le Sillon et l'œuvre de Marc Sangnier, on est moins au fait de l'action de la Fédération nationale catholique, fort développée sous la III ${ }^{e}$ République. On pourrait la penser, à cause de l'attachement aux traditions de son fondateur, le général de Castelnau, plutôt conservatrice, au mieux paternaliste. En fait le jugement peut être plus nuancé. L'œuvre sociale réalisée dans ce cadre ne manque pas de discrètes audaces. Il y a aussi le PRP (Parti démocrate populaire) fondé en 1924 par Robert Cornilleau. Il s'agit là du berceau de ce qui est devenu, en 1944, le MRP (Mouvement républicain populaire). Parmi ceux qui ont trouvé leur place dans cette démocratie chrétienne, le moindre n'est évidemment pas Robert Schuman, si engagé dans la construction de l'Europe. Une même inspiration catholique modérée a été à l'origine de mouvements plus immédiatement ambigus quant à leurs intentions. Que penser en effet de cette Fédération nationale des familles nombreuses fondée en 1921, dont l'intention est de favoriser une croissance démographique après la guerre, mais dont les responsables sont d'abord des opposants fervents au divorce? Que penser aussi de la montée en puissance, après 1949, du CNIP (Centre national des indépendants et paysans) qui regroupe des insatisfaits venus d'horizons contrastés et parfois louches?

$8 \mathrm{Au}$ fil des pages, on rencontre beaucoup de belles personnalités. Outre Robert Cornilleau et Robert Schuman déjà cités, il y a Étienne Borne, le fondateur du centre des Intellectuels catholiques ou Étienne Gilson dont l'indépendance d'esprit au début de la guerre froide lui a valu bien des ennuis. On est aussi impressionné par la variété des initiatives, associations, revues qui ont fait date dans le monde intellectuel.

On se demande pourtant si cette modération remarquable ne connait pas aussi quelques excès troublants, notamment ceux de l'Opus Dei, considéré dans un chapitre sur l'Espagne de manière bien indulgente. Que penser, dans le registre d'une atonie redoutable, de la personnalité et de l'action d'Antoine Pinay? Sa popularité réelle semble un faible argument. On se demande si les engagements réfléchis, la prudence raisonnable, d'éventuelles nuances, n'ignorent pas trop souvent des questions essentielles. On sent les catholiques modérés peu familiers de raisonnements économiques qui prendraient en charge les problèmes liés à une dynamique industrielle forte. S'ils ont été antinazis, en ont-ils vraiment mesuré les dangers ?

10 Il y a manifestement des modérés plus engagés que d'autres dans un horizon d'espérance et, à l'inverse, il y a des modérés plutôt intolérants, voire aveugles aux problèmes du temps, aux débats de la modernité.

11 Quoi qu'il en soit, grâce à la qualité des intervenants (historiens et spécialistes de sciences politiques) et à leurs exposés très informés, on apprend beaucoup. 